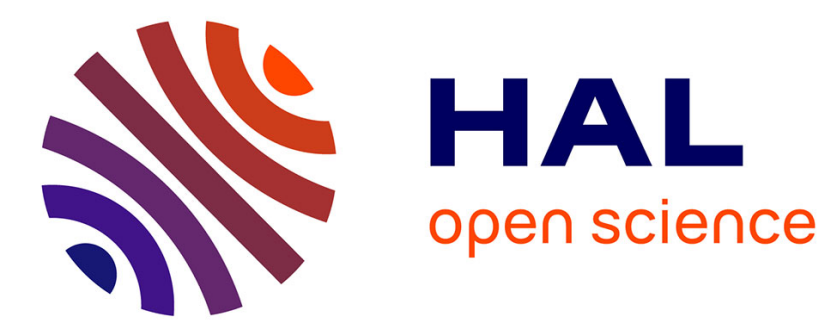

\title{
Bolide Airbursts as a Seismic Source for the 2018 Mars InSight Mission
}

J. Stevanović, N. Teanby, J. Wookey, N. Selby, J. Daubar, J. Vaubaillon, R. Garcia

\section{- To cite this version:}

J. Stevanović, N. Teanby, J. Wookey, N. Selby, J. Daubar, et al.. Bolide Airbursts as a Seismic Source for the 2018 Mars InSight Mission. Space Science Reviews, 2017, 211 (1-4), pp.525-545. 10.1007/s11214-016-0327-3 . hal-02178908

\section{HAL Id: hal-02178908 https://hal.science/hal-02178908}

Submitted on 30 Nov 2020

HAL is a multi-disciplinary open access archive for the deposit and dissemination of scientific research documents, whether they are published or not. The documents may come from teaching and research institutions in France or abroad, or from public or private research centers.
L'archive ouverte pluridisciplinaire HAL, est destinée au dépôt et à la diffusion de documents scientifiques de niveau recherche, publiés ou non, émanant des établissements d'enseignement et de recherche français ou étrangers, des laboratoires publics ou privés. 


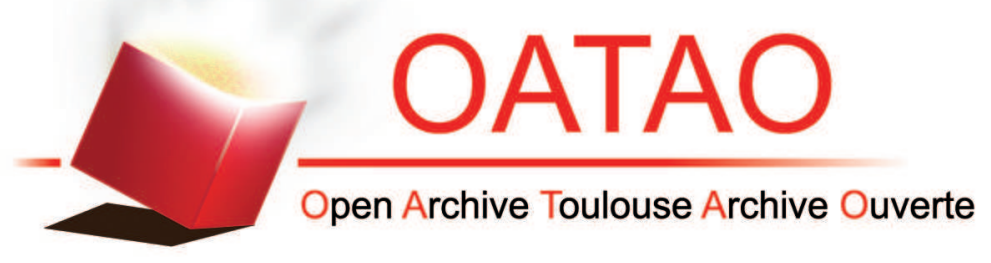

\section{Open Archive Toulouse Archive Ouverte (OATAO)}

OATAO is an open access repository that collects the work of some Toulouse researchers and makes it freely available over the web where possible.

This is an author's version published in: https://oatao.univ-toulouse.fr/21701

Official URL: https://doi.org/10.1007/s11214-016-0327-3

\section{To cite this version :}

Stevanović, Jennifer and Teanby, N. A. and Wookey, James and Selby, N. and Daubar, I. J. and Vaubaillon, Jeremie and Garcia, Raphaël F. Bolide Airbursts as a Seismic Source for the 2018 Mars InSight Mission. (2017) Space Science Reviews, 211 (1-4). 525-545. ISSN 0038-6308

Any correspondence concerning this service should be sent to the repository administrator: tech-oatao@listes-diff.inp-toulouse.fr 


\title{
Bolide Airbursts as a Seismic Source for the 2018 Mars InSight Mission
}

\author{
J. Stevanović, ${ }^{1,2}$ (D) N.A. Teanby ${ }^{1} \cdot$ J. Wookey ${ }^{1}$. \\ N. Selby ${ }^{3}$ I.J. Daubar ${ }^{4}$ J. Vaubaillon ${ }^{5}$ R. Rarcia ${ }^{6}$
}

\begin{abstract}
In 2018, NASA will launch InSight, a single-station suite of geophysical instruments, designed to characterise the martian interior. We investigate the seismo-acoustic signal generated by a bolide entering the martian atmosphere and exploding in a terminal airburst, and assess this phenomenon as a potential observable for the SEIS seismic payload. Terrestrial analogue data from four recent events are used to identify diagnostic airburst characteristics in both the time and frequency domain.

In order to estimate a potential number of detectable events for InSight, we first model the impactor source population from observations made on the Earth, scaled for planetary radius, entry velocity and source density. We go on to calculate a range of potential airbursts from the larger incident impactor population. We estimate there to be $\sim 1000$ events of this nature per year on Mars. To then derive a detectable number of airbursts for InSight, we scale this number according to atmospheric attenuation, air-to-ground coupling inefficiencies and by instrument capability for SEIS. We predict between 10-200 detectable events per year for InSight.
\end{abstract}

Keywords Meteors $\cdot$ Airbursts $\cdot$ Mars $\cdot$ Atmospheric processes

J. Stevanović

jenny@blacknest.gov.uk

1 School of Earth Sciences, University of Bristol, Wills Memorial Building, Queens Road, Bristol, BS8 1RJ, UK

2 Present address: AWE Blacknest, Brimpton, Reading, RG7 4RS, UK

3 AWE Blacknest, Brimpton, Reading, Berkshire, UK

4 Jet Propulsion Laboratory, California Institute of Technology, Pasadena, CA 91109, USA

5 IMCCE, Observatoire de Paris, PSL-Université, Paris, France

6 Institut Supérieur de l'Aéronautique et de l'Espace (ISAE-SUPAERO), Université de Toulouse, 31055 Toulouse cedex 4, France 


\section{Introduction}

An airburst is the explosion of a meteoroid (bolide) in a planetary atmosphere, before impact into its surface. On Earth, airbursts are a well-documented source of both seismic and acoustic energy (Edwards and Hildebrand 2004; Revelle et al. 2004; Arrowsmith et al. 2007; Edwards et al. 2007). A recent example is the Chelyabinsk event over Russia in early 2013 (Brown et al. 2013), which was observed optically, as well as seismically and by infrasound detectors. The mechanisms for generating seismic and acoustic signals are reviewed by Edwards et al. (2008) and summarised in Fig. 1. Here we focus on the airwave generated by the terminal blast, together with the ground coupled seismic waves and assess the possibility of these signals being detected by the InSight mission.

Typically bolides enter planetary atmospheres at very high velocity $\left(\sim 10 \mathrm{~km} \mathrm{~s}^{-1}\right)$ and thus experience a strong frictional drag and a high dynamic pressure. Airbursts occur when the dynamic pressure overcomes the intrinsic compressive strength of the bolide. In a dense atmosphere like that of the Earth, fragmentation and airbursts are likely across a wide range of material strengths. Even in the much more tenuous martian atmosphere, we still might expect to observe airbursts, since the density of the Earth's atmosphere at $35 \mathrm{~km}$ altitude is comparable to the martian atmosphere at the surface, and most airbursts on the Earth occur above $\sim 30 \mathrm{~km}$ (Bland and Artemieva 2006). There is also evidence that airbursts occur on Mars (Fig. 2), where it is possible to observe radial blast patterns with no associated crater. It is at the sub-terminal point, directly beneath the airburst location, that the acoustic energy released is most strongly coupled into the ground, thence propagating as seismic waves.

In 2018, NASA's InSight lander will deploy a single-station suite of geophysical instruments on Mars' surface to monitor planetary heat flow and seismic activity in order to determine the present state of the martian interior. One of InSight's primary science goals is to "measure the rate of meteorite impacts on the surface of Mars" (NASA 2013). However, there are expected to be very few events large enough to be globally detectable during the nominal mission, with Teanby and Wookey (2011) and Teanby (2015) predicting around 1 globally detectable event per year. Therefore, smaller local or regional events must be relied upon for a more statistically robust measurement of the current impactor flux. However, smaller bolides entering the atmosphere of a planet are more likely to fragment (assuming size invariant mechanical properties) and result in an airburst (Collins et al. 2005; Williams et al. 2014).

Airburst signals thus have the potential to play an important role in our understanding of Mars' impactor population. It follows that in order to understand the processes of meteor interactions with Mars and determine their rate of occurrence, we must be able to identify

Fig. 1 Summary of seismic and acoustic signals generated by airbursts. (A) acoustic waves generated by the super-sonic atmospheric entry; (B) airbursts; (C) seismic waves generated surface impacts; (D) Air-ground coupled seismic waves; and (E) direct airwaves. In this paper we consider sources $(\mathbf{B}, \mathbf{D}, \mathbf{E})$ with our main focus on air-ground coupled waves (D). Redrawn from Edwards et al. (2008)

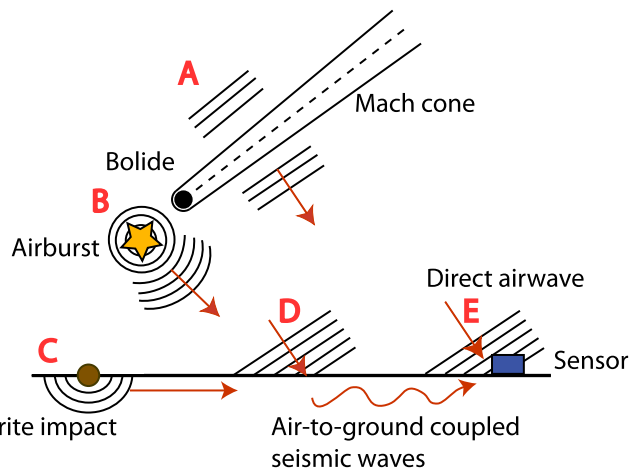



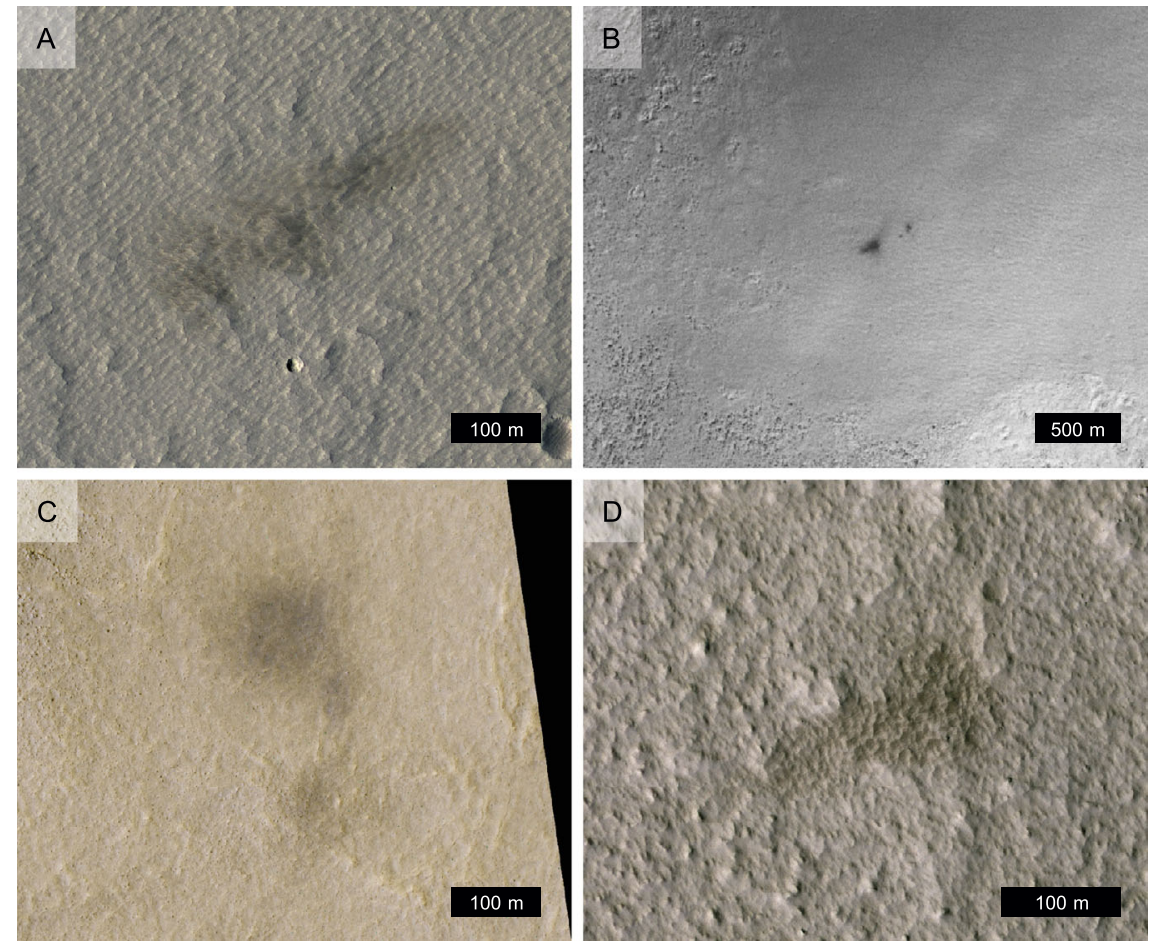

Fig. 2 Rare examples of possible surface evidence for airbursts: sites where darkening of the surface was observed between successive images in a manner consistent with the dark blast zones around new impact craters (see Daubar et al. 2016), but a corresponding impact crater is not observed. These might also be sites of aeolian activity, although the appearance of the dark areas is distinct; or a crater might exist, but be so small as to not be resolved by HiRISE. (A) HiRISE observation ESP_011505_1755 at -4.508 N, 254.337 E. (B) CTX observation P14_006559_1298_XN_50S055W at -50.057 N, 304.905 E. (C) HiRISE observation ESP_027569_2310 at 50.473 N, 161.010 E. (D) HiRISE observation ESP_043679_2230 at 42.440 N, 272.015 E. HiRISE images are enhanced false colour, North is up, and all images have been stretched for contrast

and distinguish such events in the seismic record from InSight. In this paper, we determine a diagnostic set of characteristics from seismic recordings of terrestrial airbursts, which can be used to distinguish an air-to-ground coupled wave from other seismic sources, such as marsquakes or impacts. We then go on to estimate the annual number of airburst events occurring on Mars, from current knowledge of the meteor source population (Hartmann 2005; Daubar et al. 2013; Williams et al. 2014) and an understanding of the physics behind the break-up process (Hills and Goda 1993; Collins et al. 2005; Ivanov et al. 1997). Finally, using this estimate, and by defining detectability criteria for InSight based on instrument performance, atmospheric attenuation and noise models, we estimate the number of airburst events detectable by InSight.

\section{Seismo-Acoustic Characteristics of an Airburst}

We first compile a terrestrial dataset of seismic recordings of airburst events and use these as an analogue of future events on Mars. Our aim is to understand and quantify the diagnostic 
Table 1 Selection of historical airbursts. Data from the Research and Development Support Services (RDSS) project of the US Army Space and Missile Defense Command's Monitoring Research Programme (http://www.rdss.info/)

\begin{tabular}{|c|c|c|c|c|c|}
\hline Name & Date \& time (UCT) & Size & Altitude (km) & Yield (kt TNT) & Entry velocity $(\mathrm{km} / \mathrm{s})$ \\
\hline Chelyabinsk & $\begin{array}{l}\text { 15/02/13 } \\
03: 20: 26\end{array}$ & $17-20 \mathrm{~m}$ & 23.3 & 500 & 18.6 \\
\hline Oregon ${ }^{[R D S S]}$ & $\begin{array}{l}19 / 02 / 08 \\
13: 30: 31 \pm 4\end{array}$ & - & $28 \pm 5$ & - & - \\
\hline Antarctic $^{[R D S S]}$ & $\begin{array}{l}03 / 09 / 04 \\
12: 07: 26.2 \pm 0.8\end{array}$ & - & $29 \pm 5$ & $33 \pm 17$ & - \\
\hline Neuschwanstein ${ }^{[R D S S]}$ & $\begin{array}{l}06 / 04 / 02 \\
20: 20: 17\end{array}$ & $6 \mathrm{~kg}$ & $31 \pm 4$ & 1.87 & $\begin{array}{l}\text { On entry: } 20.95 \\
\text { Terminus: } 2.4\end{array}$ \\
\hline
\end{tabular}

properties of airbursts as a source of seismic energy and to be able to distinguish them from marsquakes, impacts and other seismic sources. We recognise, however, that even for Earth where we have a well developed network of seismic stations, source characterisation is still a challenging and controversial area (Douglas 2013). It is only when several distinctive features are observed in parallel that any degree of confidence can be claimed.

\subsection{Terrestrial Analogue Airburst Data}

We obtained data from four recent airburst events between 2000-2013: the Antarctic superbolide; the Chelyabinsk super-bolide; the Neuschwanstein bolide; and the Oregon State bolide. These events were chosen because they were both relatively large and occurred recently enough to be recorded on high performance seismometers, resulting in relatively high signal-to-noise ratio (SNR) across a significant number of stations. Data were obtained from the Incorporated Research Institutions for Seismology (IRIS) database and the International Monitoring System (IMS) of the Comprehensive Nuclear Test-ban Treaty (CTBT). Event details are summarised in Table 1.

\subsection{Seismo-Acoustic Characteristics of an Airburst}

A persistent challenge facing seismologists is the problem of distinguishing different source types using only information contained within the seismic trace (Douglas 2013). This can be especially difficult with an airburst source, particularly at large distances, since only a fraction of the blast energy is coupled into the ground. There are a number of characteristic features, however, which, when observed collectively, can be taken to be diagnostic of an atmospheric airburst. The terrestrial recordings are now used to characterise airburst events in both the time and frequency domains.

\subsubsection{Airwave Arrivals}

The presence of a direct airwave arrival is the most definitive evidence of an atmospheric explosion having taken place. Figure 3 shows an example of the airwave arrival from the Chelyabinsk superbolide. Airwaves typically manifest themselves as low frequency late arrivals, that could potentially be confused with regular surface waves. The key diagnostic of 


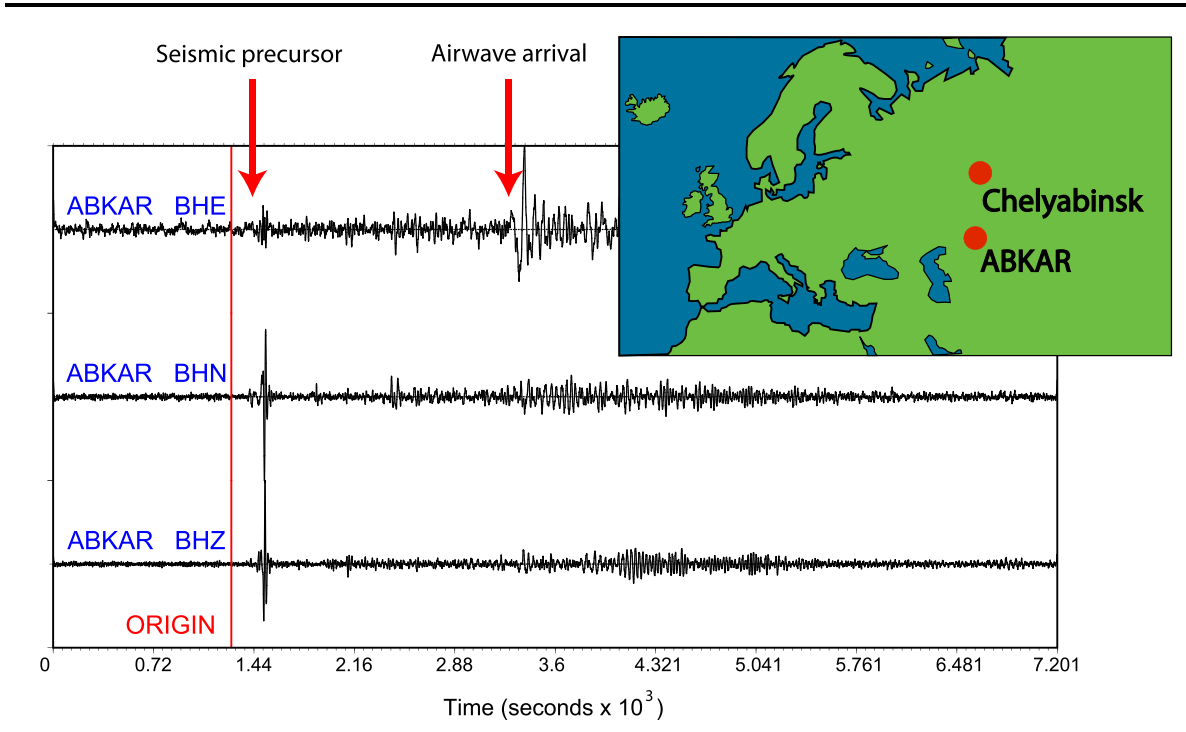

Fig. 3 Example of a broadband seismic record of the 2013, February 15th airburst event in Chelyabinsk, Russia. Origin time was at 03:20 UTC. This seismogram is taken from station ABKAR in Kazakhstan (location, inset) and filtered with a band pass filter from $1-4 \mathrm{~Hz}$ to pick out the arrivals (arrows). It shows clearly the arrival of precursor seismic energy from the ground coupled wave (D in Fig. 1) and the slower direct airwave (E in Fig. 1). BHE = East component, BHN = North component, BHZ = Vertical component

a direct airwave is an arrival with a group velocity close to the speed of sound in air (or slower in the case of atmospheric refractions). Positive identification will thus require an approximate event origin time, based on $\mathrm{P} / \mathrm{S}$ differential travel times for example.

Airwaves also result in significant atmospheric pressure variations, which have the potential to be measured by InSight's pressure sensor. The pressure sensor's primary goal is to allow pressure decorrelation to reduce seismic noise (Murdoch et al. 2016). It has a bandwidth of $0.01-1 \mathrm{~Hz}$ covering the seismic range, possibly overlapping with the peak frequency of the largest airburst events. A simultaneous detection on InSight's pressure sensor would provide excellent source discrimination information, as a conventional marsquake would not produce an associated pressure signal. However, with increasing distance from the source it becomes less likely that this airwave will be observed. Atmospheric attenuation of sound is much more severe on Mars than on Earth because $\mathrm{CO}_{2}$ has very strong molecular absorption at acoustic and sub-acoustic frequencies (Williams 2001; Bass and Chambers 2001; Petculescu and Lueptow 2007). Therefore, dissipation of the shockwave due to atmospheric attenuation, particularly in the highly attenuating $\mathrm{CO}_{2}$-dominated martian atmosphere (Chaisson and McMillan 2005; Williams 2001; Hanford and Long 2009), means that on Mars smaller airburst events will only be detectable at local scales (100's of kilometres). This makes the conversion of energy into less attenuating seismic waves all the more important.

\subsubsection{Ground Coupled Seismic Waveforms}

Energy coupled into the ground at the sub-terminal point will travel much further than the direct airwaves, especially on Mars where the solid body seismic attenuation is expected to be much lower than for atmospheric sound propagation. The characteristics of these seismic arrivals can provide evidence of an explosive source in three main ways. 


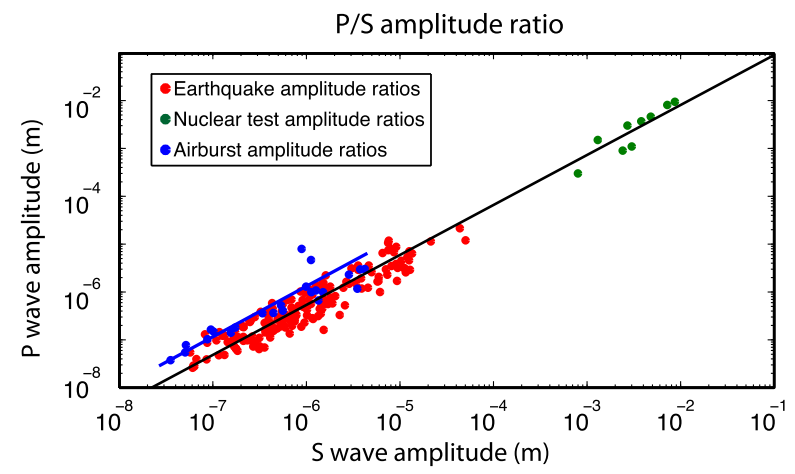

Fig. $4 \mathrm{P}$ and $\mathrm{S}$ wave amplitudes are plotted for earthquake sources, nuclear test explosion data and bolide airburst sources. The data for the earthquake source comes from Alutu volcano in the Ethiopian Rift (Wilks 2016). Earthquakes were hand-picked and span a period of around 15 months. The traces had the instrument response deconvolved to give to velocity and were then integrated to displacement. $\mathrm{P}$ amplitudes were measured from the maximum peak-to-peak amplitude between the P-onset and the S-onset while S amplitudes were measured from the maximum peak-to-peak amplitude within 2 seconds of the $S$ arrival. Subterranean nuclear test data from Crocker (1952). Airburst data are from the Oregon bolide and Chelyabinsk superbolide events

Firstly, the P/S amplitude ratio is always higher for explosions. Due to the mechanism of air-ground coupling, very little shear force is coupled into the ground. Figure 4 shows the relationship between $\mathrm{P}$-wave and $\mathrm{S}$-wave amplitudes from a series of earthquakes and subterranean nuclear test explosions compared to our airburst dataset-specifically the Chelyabinsk and Oregon State Bolides, due to their coherent signals and good SNR. It is clear from this data that the $\mathrm{P} / \mathrm{S}$ amplitude ratio is higher for the airbursts than for the other two sources. For a single seismic station, application will be challenging, as the source polarisation will be unknown and the P/S ratio will be affected by the source radiation pattern. If the source back azimuth is aligned with a fault source's $S$ nodal plane, then it is possible that a marsquake could also have a high $\mathrm{P} / \mathrm{S}$ amplitude ratio. This criteria could therefore be used to reject potential airbursts, but cannot be used to provide unambiguous detections.

Secondly, another diagnostic effect of the air to ground coupling mechanism is the polarity of the first arrival (Fig. 5). The first motion recorded at every station should theoretically be compressive, because the shockwave hitting the ground will result in a compressive wave propagating in all directions. In reality, complicating factors such as scattering or reactivation of regional fracture systems may induce a rarefactional component. With a single station, we would expect approximately half of the first arrivals from marsquakes to also have a compressive first motion. So, again, this criteria can be used to reject potential airbursts but not provide a definitive identification. The presence of noise may also make the first motion difficult to uniquely determine (e.g. Douglas 2013).

Finally, the energy from the airburst does not couple into the ground at a single point (the sub-terminal point). In reality, the shockwave will couple into the ground along a significant portion of the source-receiver path, leading to an emergent pulse envelope shape. This is commonly observed in seismic recordings of sonic booms from meteor entry and supersonic aircraft and may provide another diagnostic feature of the first arrival seismic precursors.

\subsubsection{Frequency Content}

Knowledge of the source-receiver distance and frequency content of the seismic signal observed from an airburst will allow the yield to be estimated using empirical scaling relation- 

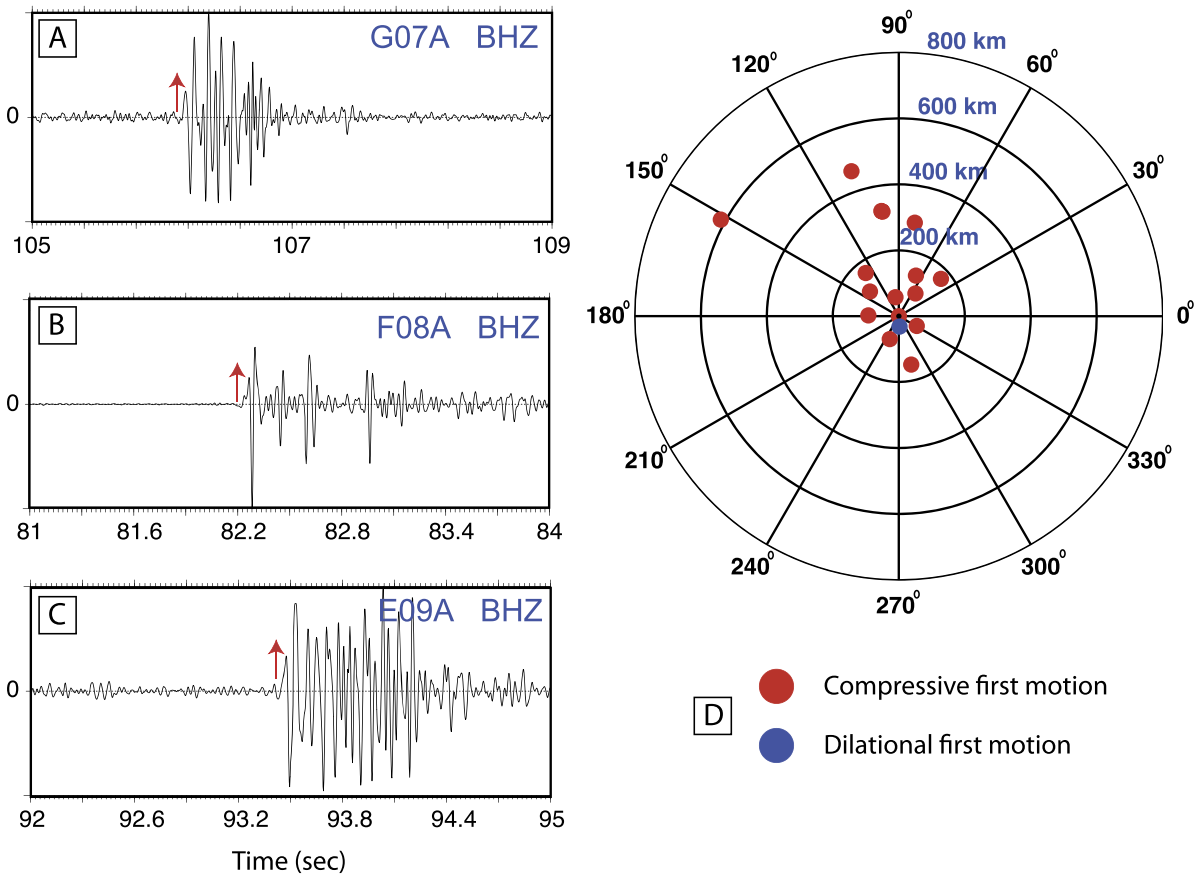

Fig. 5 The first motion recorded on a seismogram for an airburst should always be compressive. Panels A-C are examples showing this first motion for the airwave from IMS stations E09A, F09A and G07A for the Oregon Bolide event. (D) - Results of first motion from 16 IMS and USArray stations, including the examples in A-C. Back azimuth and distance are plotted. Red circles indicate compressive first motion and blue represent dilational first motion. IMS station F09A exhibits this unexpected dilational first motion which could be caused by irregularities in the geology or local station parameters

ships such as that proposed by Revelle (1997).

$$
\log _{10}\left(\frac{E_{s}}{2}\right)=3.34 \log _{10}\left(\frac{1}{f_{0}}\right)-2.58
$$

where $f_{0}$ is the dominant airwave frequency $(\mathrm{Hz})$ and $E_{s}$ is the source energy release in kilotonnes TNT equivalent ( $1 \mathrm{kT}$ TNT is equivalent to $\left.4.18 \times 10^{12} \mathrm{~J}\right)$. Note that this relation was derived for the dominant frequency of an atmospheric source from low altitude nuclear explosions. We assume that an airburst of similar yield will generate similar frequencies, which should provide a reasonable first approximation. Furthermore, as the air-coupled seismic waves are generated close to the source, it also will approximately correspond to the dominant frequency of the converted seismic wave generated at the air-regolith interface. However, with increasing source-receiver distance, the frequency content of the measured signal will be dominated by lower frequencies because of atmospheric attenuation. Therefore, corrections will need to be applied to back-out the dominant source frequency. With stations at a range of distances, the dominant frequency at the source can be determined from linear regression.

To test if this is viable we performed frequency regression for the Oregon Bolide event. Before extracting the peak arrival frequencies from each seismic component, a site correction was applied to all stations (Fig. 6) using the Horizontal to Vertical Spectral Ratio method 

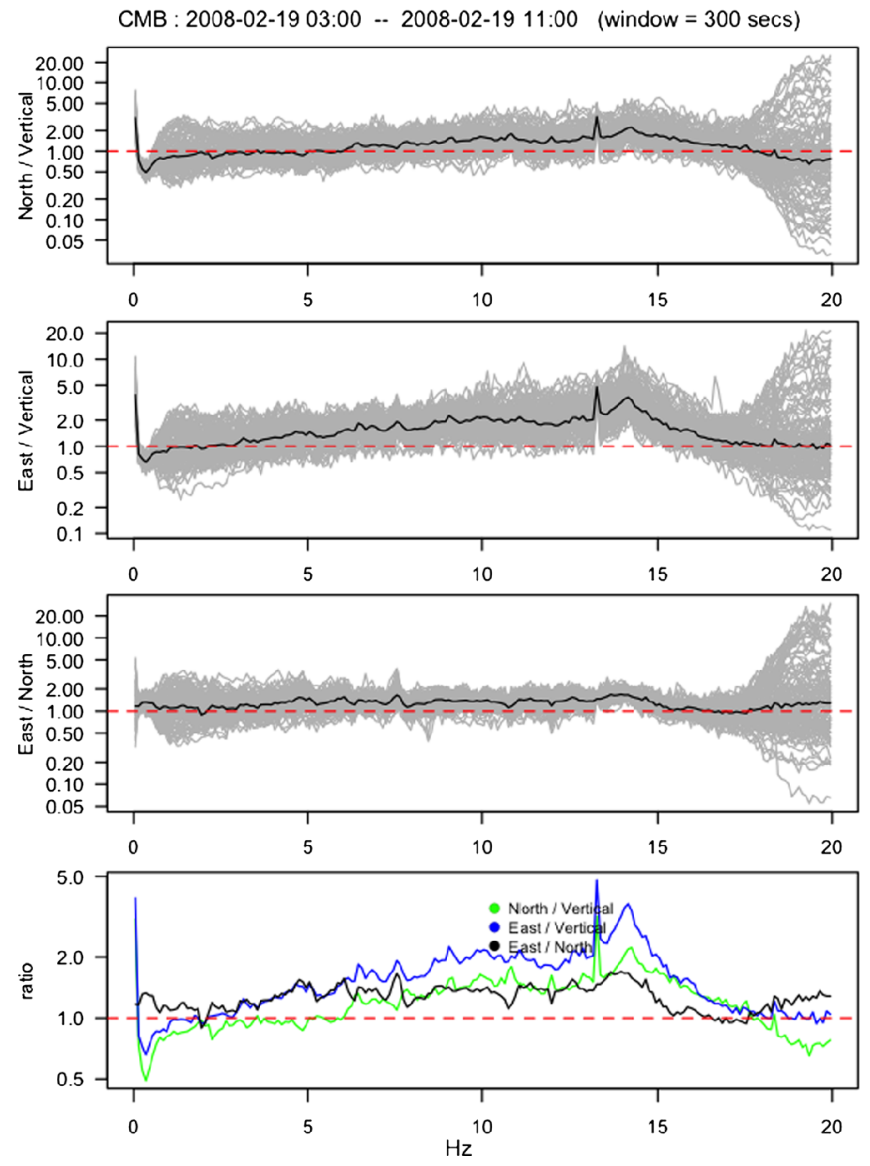

Fig. 6 Stacked spectral ratios for (from top to bottom): the North/Vertical components, East/Vertical components, East to North components and the average spectral ratio of each for comparison. Observing the East/North ratio shows that the ratio is close to unity, indicating that both horizontal components have been amplified by the same amount. Observing the horizontal to vertical spectral ratios shows a broad amplification, peaking at $14 \mathrm{~Hz}$ and a short wavelength peak at $13 \mathrm{~Hz}$ which need to be removed from the data to prevent spurious peaks appearing in the Fourier Transform

(HVSR) (Nakamura 2000), which characterises site response based on seismic noise. For the P, S, and airwave arrivals we then determined the peak frequency from a Fourier Transform, after windowing around each arrival, removing the trend, and applying a standard Hanning taper. The corrected peak frequency is shown as a function of source-receiver distance in Fig. 7. The trend of decreasing frequencies with increasing distance is clear. The regression line can be used to estimate the peak airwave frequency at zero offset, which can then be used in (1) to estimate the yield. The Oregon bolide has an estimated source frequency $f_{0}=4-20 \mathrm{~Hz}$, which implies a yield of $\approx 0.2-50 \mathrm{~kg}$ TNT equivalent.

On Mars it will not be possible to use regression to calculate the source dominant frequency because only a single station will be available. An estimate will be required instead, which could be based on modelled attenuation properties of the martian atmosphere combined with an estimated source-receiver distance. A significant amount of work is being carried out to try to understand the controlling factors acting on the attenuation. In particu- 

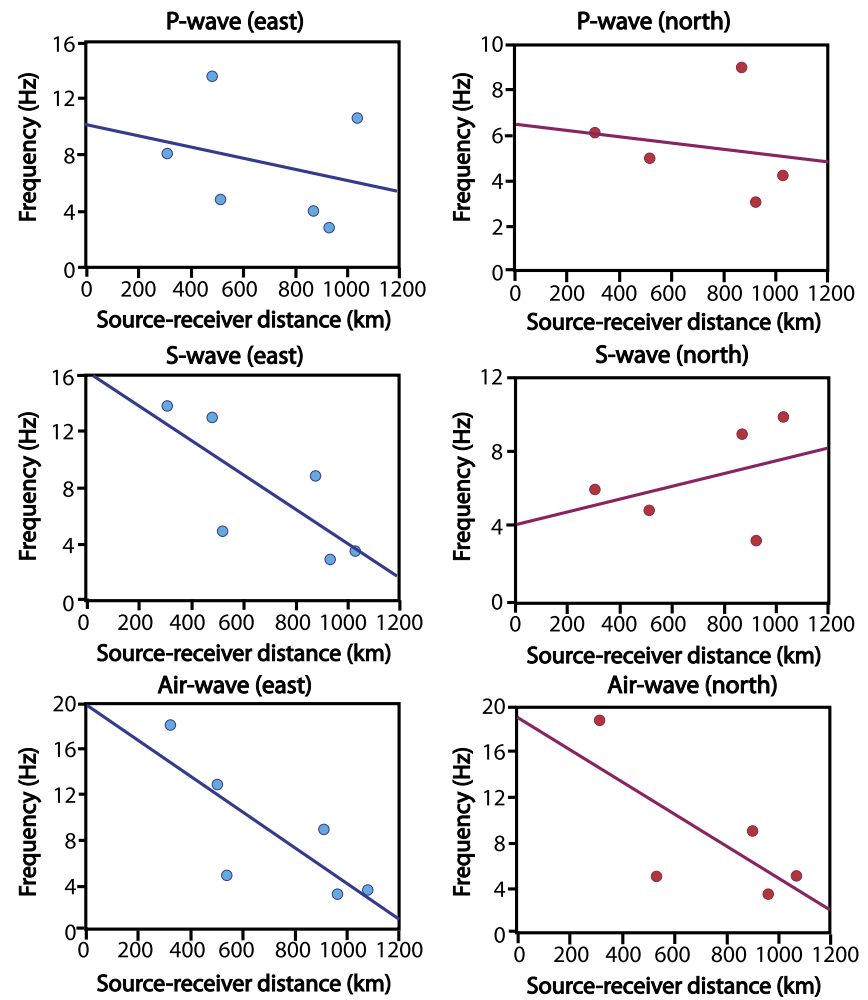

Fig. 7 Corrected horizontal component data for the Oregon Bolide, showing the P-wave, S-wave and direct Airwave arrivals. The expected trend of decreasing peak frequency with increasing distance from the sub-terminal point is now observed; the only exception being the S-wave arrival documented on the Northcomponent seismogram

lar it has been shown that altitude, source frequency, temperature structure, and prevailing wind direction all have a significant impact (Brissaud et al. 2016; Garcia et al. 2016). These, and similar studies will be of critical importance in our understanding of the effect of attenuation.

The frequency-yield relationship is important because it could help us infer the sizefrequency distribution of the Mars impactor population from the statistical proxy of small airburst events. In some cases it may also be possible to observe airburst events from associated radial blast zones in orbital imagery - this way, the location and approximate altitude will be known and observations of peak frequency may be calibrated for distance.

\section{Population of Airburst Events on Mars}

We now estimate the number of airbursts occurring on Mars. This requires consideration of the incoming meteor population at the top of the martian atmosphere and the physical processes involved in catastrophic breakup which give rise to airbursts. 


\subsection{Incident Bolide Population}

Potential impactors for the terrestrial planets come from three sources in our solar system (Ivanov 2001); asteroids, which fall either into the main belt between Mars and Jupiter, or are classed Near Earth Objects (NEOs) and whose orbits may intersect those of the terrestrial planets; Jupiter family comets, which have orbits strongly influenced by the gravitational perturbations of Jupiter; and the long-period comets, whose orbits take them into the far reaches of the solar system and which are thought to originate in the Oort Cloud. It is believed that the size-frequency distribution (SFD) of the impactors has been relatively constant in the solar system since the Late Heavy Bombardment (LHB) episode (Werner et al. 2002).

To constrain the current source population at Mars we use a combination of recent crater observations (Malin et al. 2006; Daubar et al. 2013), martian cratering isochrons (Hartmann 2005), and modified estimates of the Earth source population (Brown et al. 2002b).

Brown et al. (2002b) use satellite observations of impact flashes to estimate the source population of bolides hitting the top of the Earth's atmosphere to be:

$$
\log _{10}\left(N_{\oplus}\right)=a_{\oplus}-b_{\oplus} \log _{10} E
$$

where $N_{\oplus}$ is the cumulative number of impactors hitting the Earth per year with an energy greater than or equal to $E$ measured in kilo-tonnes TNT. The constants $a_{\oplus}$ and $b_{\oplus}$ are empirically fitted constants, with values of $a_{\oplus}=0.5677$ and $b_{\oplus}=0.9$ (Brown et al. 2002b).

To map this source population to Mars we rescale the distribution as follows:

$$
\log _{10}(N)=a_{\oplus}-b_{\oplus} \log _{10} E-b_{\oplus} \log _{10} \frac{v_{e}^{2}}{v_{m}^{2}}+\log _{10} \frac{r_{m}^{2}}{r_{e}^{2}}+\log _{10} \frac{v_{m}}{v_{e}}+\log _{10} f_{m}
$$

where $v_{e}=20.3 \mathrm{~km} \mathrm{~s}^{-1}$ is the mean impactor velocity for Earth (Brown et al. 2002b), $v_{m}=$ $10.2 \mathrm{~km} \mathrm{~s}^{-1}$ is the mean impactor velocity at Mars (Williams et al. 2014), $r_{e}=6371 \mathrm{~km}$ is Earth's radius, $r_{m}=3390 \mathrm{~km}$ is Mars' radius, and $f_{m}=1.885$ is the ratio of number density of impactors at Mars (number $/ \mathrm{km}^{3}$ of a given diameter) to the number density of impactors at Earth (Williams et al. 2014). The four correction terms on the right hand side of (3) respectively correct for: differences in kinetic energy due to difference in mean impactor velocity; differences in the surface area of Mars and Earth; reduction in flux due to the slower mean impactor velocity at Mars; and ratio of impactor number densities at Mars compared to Earth. This can be simplified to:

$$
\log _{10}(N)=a-b_{\oplus} \log _{10} E
$$

where $a=-0.54$ based on Brown et al. (2002b) and Williams et al. (2014).

As a check on this result we compare this to new crater observations from differential imaging campaigns (Malin et al. 2006; Daubar et al. 2013) and martian crater isochrons (Hartmann 2005). Malin et al. (2006) observed 20 new craters with Mars Global Surveyor and Daubar et al. (2013) detected 44 using Mars Reconnaissance Orbiter. Both studies use low albedo impact blast patterns caused by dust clearing to detect recent impacts, then use differential imaging to confirm the presence of a new crater. The time between images and spatial coverage of the areas studies are then used to determine present-day cratering rates. The derived cratering rates are within a factor of three of the independently determined isochrons of Hartmann (2005). To compare these cratering results to the bolide energy distribution in (4), differential crater numbers were first binned by size to obtain cumulative 
Fig. 8 Cumulative yield-frequency distribution of bolides incident on Mars. Our assumed bolide source population is constrained by recent new crater observations (Malin et al. 2006; Daubar et al. 2013) and is also consistent to within a factor of 3 with Hartmann (2005)'s isochrons and a mapping of the Earth small impactor population (Brown et al. 2002b) to Mars. Note the flattening of the observed crater-derived curves at low energies is due mainly to the difficulty of detecting very small craters. Equivalent bolide diameters and atmosphere-free crater diameters are also shown for comparison and were calculated assuming a representative density of $2570 \mathrm{~kg} \mathrm{~m}^{-3}$ and an impact velocity of $10.2 \mathrm{~km} \mathrm{~s}^{-1}$ (Williams et al. 2014)

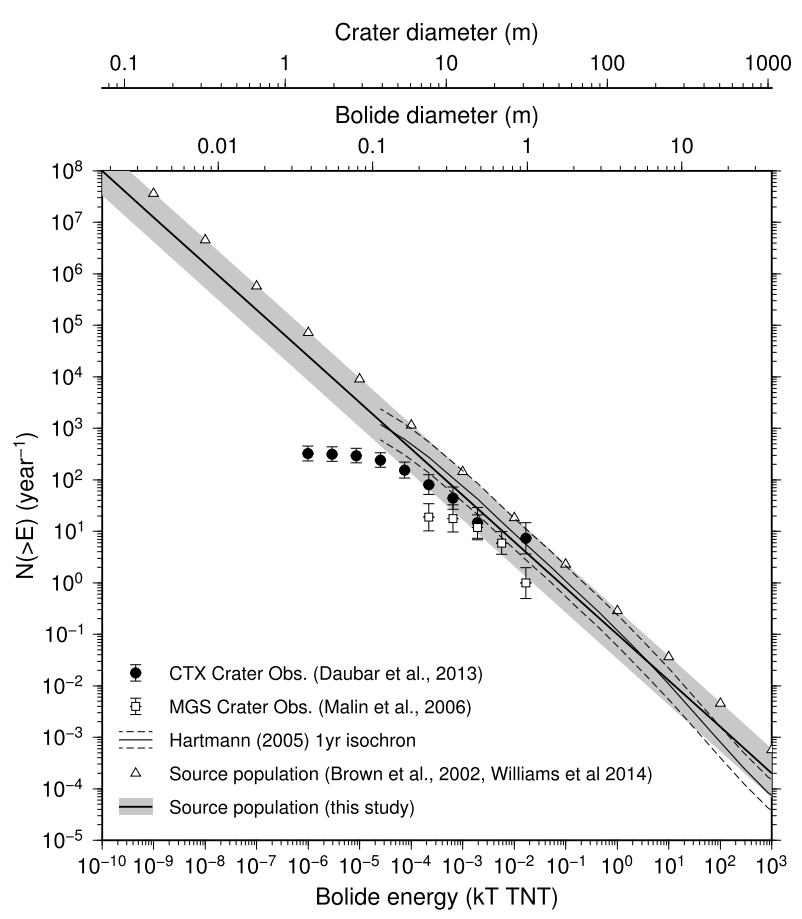

cratering rates: i.e. the number of new craters larger than a given diameter forming on Mars per year. Crater diameters were then converted into equivalent bolide kinetic energies using the scaling relations in Teanby and Wookey (2011) assuming no energy loss during atmospheric entry.

Large craters should be minimally effected by Mars' atmosphere and should be consistent with the source population predictions. Williams et al. (2014) found the effects of atmospheric fragmentation are most significant for 2-20 m craters, so we regard $50 \mathrm{~m}$ craters and above as being minimally effected by the atmosphere. Figure 8 compares the modified Brown et al. (2002b) distribution to that inferred from cratering records. As expected the small craters fall below the predicted source population due to a combination of fragmentation, ablation, and detection bias. Equation (4) is consistent with the upper range of Hartmann (2005)'s 1-year isochron for our diameter range of interest, although we note that the Hartmann isochrons include atmospheric filtering from Popova et al. (2003), which reduces the number of small diameter craters $(<50 \mathrm{~m})$. The new crater observations are around a factor of three below the isochron-based estimates (Malin et al. 2006; Daubar et al. 2013), but are consistent to within error.

In the rest of this paper, to cover the range of estimates in the literature we use a value of $a=-1 \pm 0.5$ and $b_{\oplus}=0.9$ where the uncertainty on $a$ is chosen to give a factor of three error in $N$. Using (4) with these values then gives a conservative estimate of the source population at Mars.

\subsection{Airburst Forming Process}

Airbursts occur when an incoming meteor or asteroid interacts with a planetary atmosphere in such a way that critical failure occurs. Upon entry into a planetary atmosphere, a bolide 
will experience aerodynamic drag and dynamic pressure, which both tend to increase with decreasing altitude due to increasing atmospheric density. Stage one of an airburst occurs when the compressive strength of the meteor, $S_{\text {bolide }}$, is exceeded by the dynamic pressure (stagnation pressure) acting on its leading hemisphere. Stagnation pressure $P_{s}$ is given by:

$$
P_{s}=\rho_{a t m} V_{B}^{2}
$$

where $V_{B}$ is bolide velocity and $\rho_{a t m}$ is the atmospheric density (Hills and Goda 1993; Collins et al. 2005). Atmospheric density $\rho_{\text {atm }}$ as a function of altitude $z$ can be reasonably approximated using:

$$
\rho_{a t m}=\rho_{0} \exp \left(\frac{-z}{H}\right)
$$

where $H=11.1 \mathrm{~km}$ is the atmospheric scale height and $\rho_{0}=0.02 \mathrm{~kg} \mathrm{~m}^{-3}$ is the surface atmospheric density (Williams 2004b). Throughout our analysis we neglect the effects of ablation, which is a reasonable approximation for meteoroid velocities of $\sim 10 \mathrm{~km} \mathrm{~s}^{-1}$ or less (Williams 2004b). In the absence of ablation, the bolide velocity $V_{B}$ along its trajectory can be calculated using (Collins et al. 2005):

$$
V_{B}=V_{0} \exp \left(\frac{-3 \rho_{a t m} C_{D} H}{4 \rho_{B} D \sin \theta}\right)
$$

where $V_{0}$ is the entry velocity, $C_{D}$ is the drag coefficient, $\rho_{B}$ is the bolide density, $D$ is the bolide diameter, and $\theta$ is the entry angle from horizontal. We assume $C_{D}=0.91$ based on supersonic gas gun experiments with spheres by Hodges (1957), which is consistent with modelling by Carter et al. (2009). The criteria for initiation of an airburst with strength $S_{\text {bolide }}$ is (Tirskiy and Khanukaeva 2004; ReVelle 2004; Ceplecha and ReVelle 2005):

$$
\rho_{\text {atm }} V_{B}^{2} \geq S_{\text {bolide }}
$$

While this criteria is met, the bolide will deform.

For Earth's dense atmosphere, the strength of most plausible impactor materials is well below the dynamic pressures encountered for a wide range of bolide sizes. In fact the steepness of the dynamic pressure curves means that on Earth the material strength does not play a critical role in determining if deformation occurs as the strength is exceeded at altitudes above $10 \mathrm{~km}$ for most small impactors. However, dynamic pressures on Mars are much lower due to the more tenuous atmosphere. The typical strength of carbonaceous chondrite laboratory samples $(\approx 30 \mathrm{MPa}$, Tsuchiyama et al. 2009) is never exceeded, implying that deformation and subsequent airbursts would never be initiated. Based on the imaging results we know that at least some airbursts do occur, suggesting that the effective strength of bolides could in fact be much less than that measured in laboratory samples.

Current knowledge of effective impactor strength is based on observations and modelling of atmospheric fireball events on Earth combined with laboratory measurements on millimetre to decametre size meteorites. In many studies the strength is assumed to be massdependent, with larger impactors being weaker due to the increased abundance of fractures. This is usually expressed as $S_{\text {bolide }}=S_{0}\left(m_{0} / m_{\text {bolide }}\right)^{c}$, where $S_{0}$ and $m_{0}$ are a reference strength and mass and $c$ is an empirically derived constant (e.g. Popova et al. 2011). However, the distribution of strengths inferred from well documented falls is highly scattered and as a result $c$ is not well determined,. This can be seen in Popova et al. (2011) (their Fig. 4), where derived strengths take values in the range 0.01-10 MPa with no definitive 
Fig. 9 Trajectories of objects entering the atmospheres of the Earth and Mars as a function of their size. Vertical lines represent average values of strength for Carbonaceous (blue) and Iron (red) meteors. The intersection of trajectory curves with these values marks altitude of onset of deformation
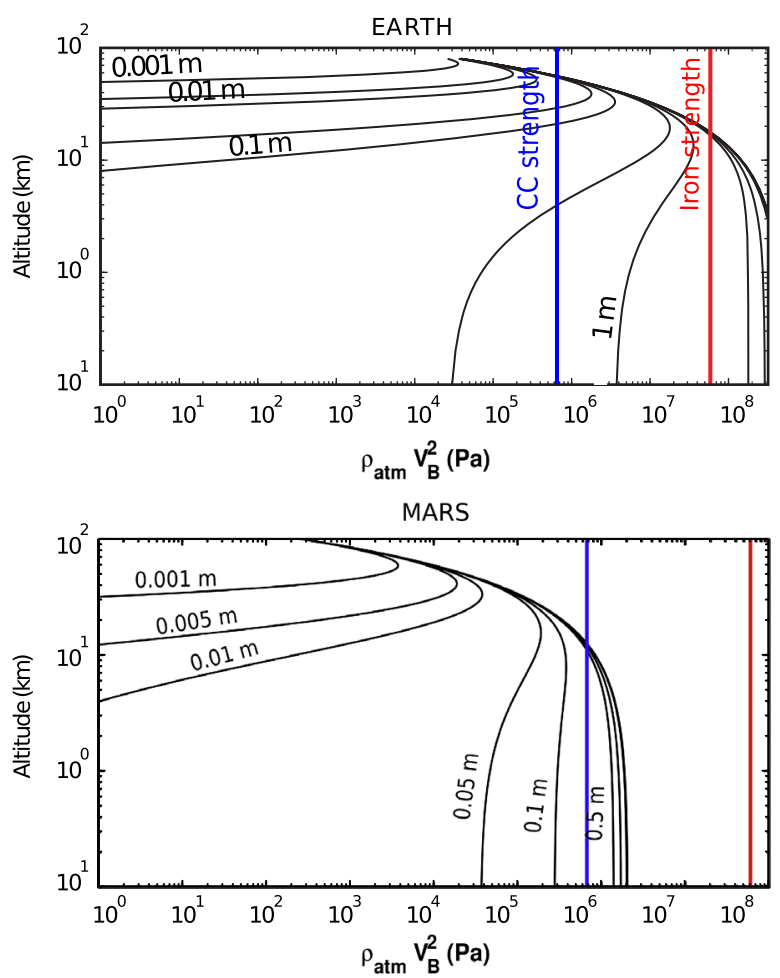

trend. Therefore, our approach is to take a single representative value for $S_{\text {bolide }}$. We assume a material strength of $S_{\text {bolide }}=0.65 \mathrm{MPa}$, which was found to provide a good match to martian crater clusters when used in atmospheric entry modelling by Williams et al. (2014). Our assumed value of $0.65 \mathrm{MPa}$ is also consistent with measurements of the strength of fractured stony material, which could be appropriate for chondritic bolide types (1.0 MPa, Hoek 1983).

Figure 9 shows the trajectories of various impactor sizes in terms of dynamic pressure using the parameters in Table 2. Figure 9 also shows typical bulk compressive strengths for Iron and Carbonaceous Chondrite meteors. Where these lines intersect, the criteria in (8) has been exceeded and deformation will begin.

Stage two of an airburst is the so-called pancaking phase (Collins et al. 2005; Bland and Artemieva 2006; Stulov 2010), whereby the bolide begins to deform and spread laterally. If the deformation is large enough, catastrophic fragmentation and an airburst will occur. Here we follow the methodology developed by Collins et al. (2005), which we briefly summarise below.

If the conditions of (8) are met, then the rate of deformation is controlled by the physical properties of the bolide according to the parameter $I_{f}$.

$$
I_{f}=\frac{4.07 C_{D} H S_{\text {bolide }}}{\rho_{b} D V_{0}^{2} \sin \theta}
$$

If $I_{f}$ is greater than 1 , then little to no deformation will occur and the bolide will impact the surface without having undergone any significant alteration. Conversely, if $I_{f}$ is less than 1 , significant deformation will occur. The altitude $z_{\text {def }}$ where deformation begins can 
Table 2 Parameters used in the calculation of bolide velocity and ambient atmospheric density, both as a function of altitude. [1]-Bland and Artemieva (2006), [2]-Britt and Consolmagno (2003), [3]-Hodges (1957), [4]-Williams (2004a), [5]-Morrison et al. (1994), [6]-Williams (2004b), [7]-Kuznetsova and Gritsevich (2014)

\begin{tabular}{llll}
\hline Parameter & Iron & OC & CC \\
\hline$\rho_{B}\left(\mathrm{~kg} / \mathrm{m}^{3}\right)$ & $7800^{[1]}$ & $3400^{[1]}$ & $2110^{[2]}$ \\
$\theta\left(^{\circ}\right)$ & 45 & 45 & 45 \\
Earth & & & \\
$C_{D}$ & $0.91^{[3]}$ & $0.91^{[3]}$ & $0.91^{[3]}$ \\
$H(\mathrm{~km})$ & $8.5^{[4]}$ & $8.5^{[4]}$ & $8.5^{[4]}$ \\
$\rho_{0}\left(\mathrm{~kg} / \mathrm{m}^{3}\right)$ & $1.217^{[4]}$ & $1.217^{[4]}$ & $1.217^{[4]}$ \\
$V_{0}(\mathrm{~km} / \mathrm{s})$ & $20^{[5]}$ & $20^{[5]}$ & $20^{[5]}$ \\
Mars & & & \\
$C_{D}$ & $0.91^{[3]}$ & $0.91^{[3]}$ & $0.91^{[3]}$ \\
$H(\mathrm{~km})$ & $11.1^{[6]}$ & $11.1^{[6]}$ & $11.1^{[6]}$ \\
$\rho_{0}\left(\mathrm{~kg} / \mathrm{m}^{3}\right)$ & $0.020^{[6]}$ & $0.020^{[6]}$ & $0.020^{[6]}$ \\
$V_{0}(\mathrm{~km} / \mathrm{s})$ & $15^{[7]}$ & $10^{[7]}$ & $10^{[7]}$ \\
\hline
\end{tabular}

be calculated using:

$$
z_{\text {def }}=-H\left(\ln \left(\frac{S_{\text {bolide }}}{\rho_{0} V_{0}^{2}}\right)+1.308-0.314 I_{f}-1.303 \sqrt{1-I_{f}}\right)
$$

The length scale over which this deformation occurs is given by $l_{d i s p}$ :

$$
l_{\text {disp }}=D \sin \theta \sqrt{\frac{\rho_{b}}{C_{D} \rho_{a t m}\left(z_{d e f}\right)}}
$$

The dispersion diameter $D_{\text {disp }}$ of the bolide, i.e. the width of the pancake, at a given altitude is then given by:

$$
D_{\text {disp }}=D \sqrt{1+\left(\frac{2 H}{l_{\text {disp }}}\right)^{2}\left(\exp \left(\frac{z_{\text {def }}-z}{2 H}\right)-1\right)^{2}}
$$

The criteria we use (after Collins et al. 2005) to define the moment when an airburst occurs in this process is when $D_{\text {disp }} \geq 7 \mathrm{D}$, or when the pancaking radius exceeds seven times the original bolide diameter. It is at this point that all of the kinetic energy of the incident meteor can be said to have been deposited in the atmosphere as a terminal blast. Note that the pancake criteria is not supposed to be an accurate representation of what happens during an airburst, but is simply a way to parameterise the process and give a reasonable match to observed break-up altitudes (Collins et al. 2005).

\subsection{Airburst Population}

To determine the population of airbursts on Mars we combine the size-frequency distribution from Sect. 3.1 with the theory outlined in Sect. 3.2. We consider three types of bolidesIron; Ordinary Chondritic (OC); and Carbonacous Chondritic (CC)—whose properties are summarised in Table 2. Mars' bolide population is expected to be similar to that of the nearEarth asteroids, which is mostly composed of carbonaceous and ordinary chondrites (Brown et al. 2002b). 

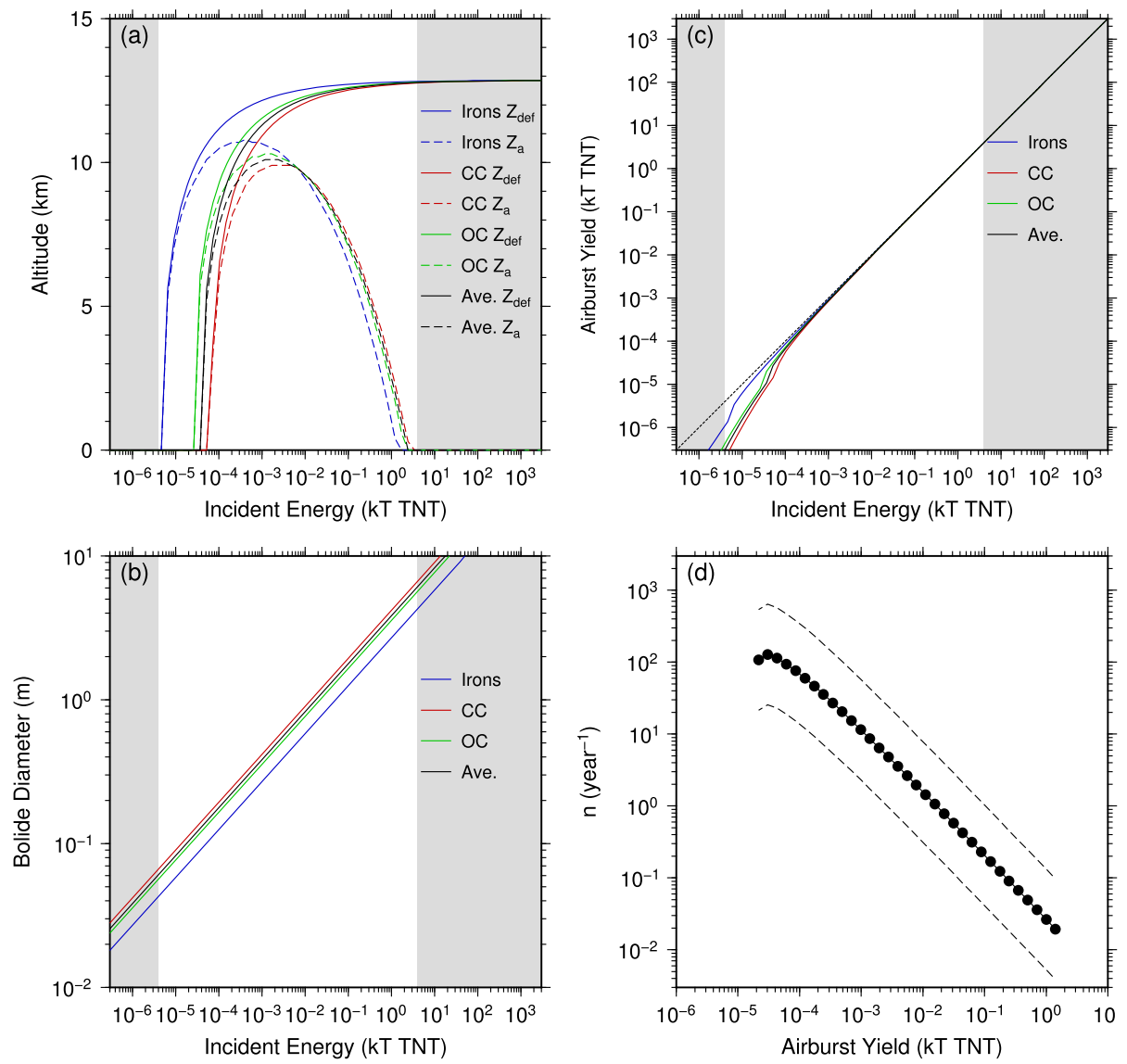

Fig. 10 Airburst population. (a) The altitude where deformation begins $\left(z_{\text {def }}\right)$ and the altitude where the pancake criteria is met and the airburst occurs $\left(z_{a}\right)$ for a range of bolide compositions including irons, carbonaceous chondrites, ordinary chondrites, and an "average" composition midway between ordinary and carbonaceous chondrites. Grey areas indicate energies where airburst formation is less favourable: meteoroids with energies above $1 \mathrm{kT}$ TNT do not lose significant kinetic energy from drag during entry and deformation is slow enough that they impact the surface before the pancaking criteria is met; whereas for energies below $10^{-5} \mathrm{kT}$ TNT atmospheric drag reduces the velocity of the impactors so rapidly that the dynamic pressure never exceeds the material strength. (b) Equivalent bolide diameters assuming the densities in Table 2. (c) Airburst yield, as defined by the kinetic energy remaining when deformation begins. The smallest impactors lose much of their kinetic energy from atmospheric drag, whereas the larger impactors' energies are largely unaffected. (d) Our final airburst source population $n$, where $n$ is the number or airbursts occurring in Mars' atmosphere per year in bins with a fractional width of $\sqrt{2}$

Figure 10 shows the altitude where airbursts occur for a given incident energy. In these calculations we assume representative values for entry angle $\left(45^{\circ}\right)$, impactor velocity $\left(10.2 \mathrm{~km} \mathrm{~s}^{-1}\right)$, and bolide strength $(0.65 \mathrm{MPa})$. These are representative population-mean values only. In reality the spread in entry angle, velocity, and composition of individual events will lead to a spread in airburst altitudes. However, these effects are expected to be small compared to the uncertainty introduced by the impactor population, so we consider the mean values only for simplicity. 
Small bolides with diameters less than $\sim 0.1 \mathrm{~m}$ are slowed down by atmospheric drag so much that dynamic pressure never exceeds their strength and they result in a low velocity surface impact. Mid-sized bolides in the $\sim 0.1-2 \mathrm{~m}$ range are less effected by drag, so retain enough velocity that their strength is exceeded by dynamic pressure, which results in an airburst. Large bolides over $\sim 2 \mathrm{~m}$ also encounter dynamic pressures which exceed their strength, but are not significantly slowed by the atmosphere and so do not have enough time to meet the pancaking criteria - these also impact the surface. Therefore, airbursts only form for a narrow range of impactor energies from $\sim 10^{-5}-10^{0} \mathrm{kT} \mathrm{TNT}$. The maximum altitude an airburst occurs is around $10 \mathrm{~km}$ for energies of $\sim 10^{-3} \mathrm{kT}$ TNT.

Figure 10d summarises our airburst population as a function of yield, where we assume that the yield of the airburst is equal to the kinetic energy of the bolide at the onset of deformation. This population contains a factor of three error from the overall martian bolide population estimates, but also at least a further factor of three error due to the uncertainty in bolide strength and the airburst process. Therefore, we assume a factor of five uncertainty in these estimates. Nominally, we estimate $\sim 1000$ airbursts per year occurring on Mars with yields of $\sim 10^{-5}-10^{0} \mathrm{kT}$ TNT. The majority of these are at the lowest energies and will be extremely challenging to detect. Only $\sim 50$ events per year are expected to have yields over $10^{-3} \mathrm{kT}$ TNT. A lower bound estimate of 0.8 airburst events per year is derived from observation of crater-free radial blast patterns observed in the dusty regions of Mars in a study by Daubar et al. (2013), although no systematic search has ever been carried out for these airbursts.

\section{Estimated Airburst Detectability with InSight}

Detectability of an airburst depends not only on the yield of the terminal blast, but also on martian atmospheric properties and air-ground coupling efficiency, which in turn depends on the dominant frequency generated in the blast and the altitude at which it occurs. Estimating the detection rates contains considerable uncertainty and at present relies on many poorly constrained processes. Our approach here is to make order of magnitude estimates of the detection rates based on terrestrial analogues for the seismic amplitude generated during atmospheric explosions.

Based on scaling relations derived by Gupta and Hartenberger (1981), Brown et al. (2002a) propose the following relationship relating the yield of an explosion $Y$ (kT TNT) to the Rayleigh wave air-ground coupled wave amplitude $v_{g}\left(\mathrm{~m} \mathrm{~s}^{-1}\right)$ :

$$
Y=\frac{\chi r^{2}\left(2.748 \times 10^{2} \alpha v_{g}\right)^{1.738}}{\gamma}
$$

where $r$ is the source-receiver range (m), $\alpha$ is the coupling factor, $\gamma$ is a factor for surface consolidation, and $\chi$ is the transmissivity (defined as the reciprocal of the transmission coefficient $T$ ). Here we follow Brown et al. (2002a) and use $\gamma=0.1$ and $\alpha=10^{-6}$, which are considered appropriate for unconsolidated sediment. Note that $\alpha$ has a large uncertainty and values in the range $10^{-7}-10^{-4}$ have been used in the literature (see discussion in Brown et al. 2002a). Transmissivity $\chi$ is dependent on the impedance contrast between the air and the ground (where impedance is defined as the product of the wave velocity and the density of the medium through which is travels) and is defined by:

$$
\chi=\frac{1}{T}=\frac{Z_{1}+Z_{0}}{2 Z_{0}}
$$


where $Z_{0}$ is the impedance of the air and $Z_{1}$ is the impedance in the ground. We take the impedance of air to be $4.8 \mathrm{Nsm}^{-3}$ (calculated assuming a martian acoustic velocity of $240 \mathrm{~m} / \mathrm{s}^{-1}$ and an atmospheric surface density of $0.02 \mathrm{~kg} / \mathrm{m}^{3}$ ) and the impedance of the unconsolidated sandy soil to be $153.3 \mathrm{Nsm}^{-3}$ (assuming a regolith wave velocity of $105 \mathrm{~m} / \mathrm{s}^{-1}$ (Watkins and Kovach 1973) and a soil density of $1460 \mathrm{~kg} / \mathrm{m}^{3}$ (Balco and Stone 2003)). This results in a transmissivity of $1.5 \times 10^{4}$ between the martian atmosphere and its unconsolidated regolith layer.

On Mars, we must account for additional attenuation by the $\mathrm{CO}_{2}$ atmosphere. Attenuation of sound waves occurs via viscous damping, thermal conduction, and excitation and relaxation of molecular vibrations and rotational modes (Williams 2001; Brissaud et al. 2016; Garcia et al. 2016). The main contributor to absorption on Mars is molecular relaxation. Here we use the approach outlined in Brissaud et al. (2016) for absorption due to viscous damping and thermal conduction, with additional $\mathrm{CO}_{2}$ molecular absorption following Garcia et al. (2016) for a wind-free nominal Mars atmospheric temperature-pressure profile. The total attenuation is calculated by integrating each absorption contribution along the atmospheric ray path from the airburst altitude to the surface in a layered atmospheric model (see Garcia et al. 2016, for further details of the attenuation calculation). Here, we assume a vertical path through Mars' atmosphere from the airburst altitude to the surface and define the total attenuation in terms of an attenuation factor $\beta$, where $\beta$ is defined such that the ground velocity predicted on Mars is the ground velocity predicted on Earth multiplied by $\beta$. For our application $\beta$ ranges from $\sim 0.7$ for the smallest high frequency airbursts, to $\sim 1$ (negligible attenuation) for the largest airburst events.

Equation (13) can now be modified for attenuation to determine the maximum detection range $x_{d e t}$ for a given airburst yield:

$$
x_{d e t}=\frac{Y \gamma}{\chi\left(2.748 \times 10^{2} \alpha \beta^{-1} n_{v}\right)^{1.738}}
$$

where $n_{v}$ is the minimum detectable ground velocity, which is determined by the ambient noise acceleration spectral density $p_{a}$ according to (Havskov and Alguacil 2004):

$$
n_{v}=1.25 \frac{p_{a}}{2 \pi \sqrt{f_{1} f_{2}}} \overline{f_{2}-f_{1}}
$$

where $f_{1}$ and $f_{2}$ are the bandwidth of the signal of interest. Based on the predicted frequency content of the airbursts we set $f_{1}=0.1 \mathrm{~Hz}$ and $f_{2}=10 \mathrm{~Hz}$. We use two simple noise models: a low noise case based on the Very Broad Band (VBB) seismometer performance at $1 \mathrm{~Hz}$ of $10^{-9} \mathrm{~ms}^{-2} \mathrm{~Hz}^{-1 / 2}$; and a high noise case based on the Short Period (SP) seismometer performance at $10 \mathrm{~Hz}$ of $10^{-8} \mathrm{~ms}^{-2} \mathrm{~Hz}^{-1 / 2}$ (Mimoun et al. 2016).

Figure 11 summarises the detectability ranges for our predicted airburst source population. For a given airburst yield and noise level we estimate the maximum range $x_{d e t}$ at which this could be detected, which is used to calculate the fraction of Mars $f_{\text {det }}$ over which this event would be detectable according to (Teanby and Wookey 2011):

$$
f_{\text {det }}=\frac{1-\cos \left(\min \left[\pi, \frac{x_{\text {det }}}{r_{\text {mars }}}\right]\right)}{2}
$$

The number of detectable airburst in each $\sqrt{2}$-width yield bin is then given by:

$$
n_{\text {det }}(Y)=n(Y) f_{\text {det }}
$$



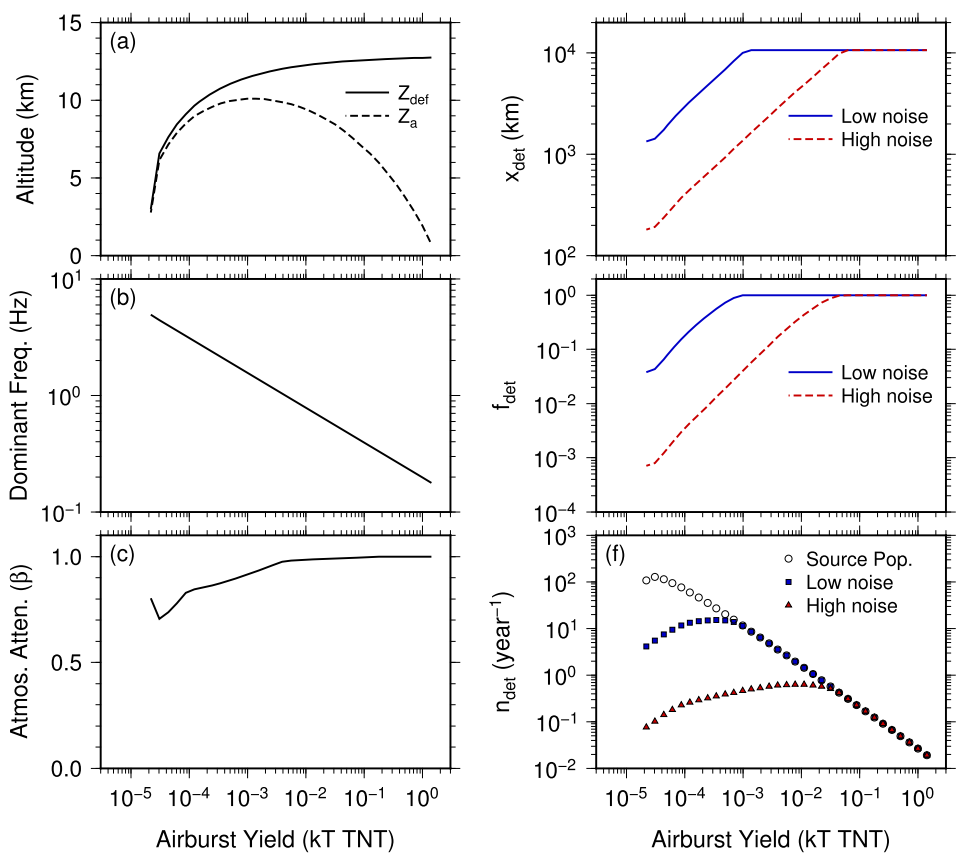

Fig. 11 Airburst source properties as a function of airburst yield assuming a mean bolide density of $2750 \mathrm{~kg} \mathrm{~m}^{-3}$, a mean entry angle of $45^{\circ}$, and a mean incident velocity of $10.2 \mathrm{~km} \mathrm{~s}^{-1}$. (a) Deformation altitude $\left(z_{d e f}\right)$ and airburst altitude $\left(z_{a}\right)$. (b) Dominant seismo-acoustic source frequency based on Revelle (1997). (c) Atmospheric attenuation coefficient $\beta$. Note that the exact value of $\beta$ will depend on the temperature profile and prevailing wind (Garcia et al. 2016). (d) Maximum ground-coupled Rayleigh wave detection range for a given yield using modified scaling of Brown et al. (2002a). (e) Corresponding fraction of Mars over which airburst is detectable. (f) Number of detectable airbursts in $\sqrt{2}$ yield bins compared to the airburst source population. Both low noise $\left(10^{-9} \mathrm{~ms}^{-1} \mathrm{~Hz}^{-1 / 2}\right)$ and high noise $\left(10^{-8} \mathrm{~ms}^{-1} \mathrm{~Hz}^{-1 / 2}\right)$ cases are shown

where $n(Y)$ is the airburst source population shown in Fig. 10(d), and is also defined incrementally in $\sqrt{2}$ bins.

The overall estimated detection rates for each noise case are shown in Fig. 11(f). For the high noise model, we predict $\sim 10$ detectable airbursts per year, whereas for the low noise case we predict $\sim 200$ detectable airbursts per year. These estimates have an uncertainty of at least one order of magnitude. The primary sources of uncertainty come from the coupling factor $\alpha$, the attenuation factor $\gamma$, atmospheric attenuation, source population estimates, and uncertainties in modelling the airburst process.

\section{Conclusion}

We predict $\sim 10-200$ detectable airburst events per year using InSight's seismometers. Large, globally detectable events are unlikely to occur over the timescale of the nominal mission. Therefore, smaller regional events will act as an important statistical proxy for the larger meteoroid population. Airburst detection will contribute to the success of the Level 1 mission goal to "measure the rate of meteorite impacts on the surface of Mars". For comparison, Panning (2016) summarise literature estimates of predicted seismicity from other 
sources, namely marsquakes and impacts. On regional scales $\sim 100$ marsquakes and $\sim 10$ surface impacts are expected to be detectable per year, also with order of magnitude uncertainties. Therefore, airbursts provide comparable predicted activity and should be an important seismic source.

It is therefore imperative that we are able to recognise an airburst event in the seismic record. We discuss distinctive characteristics that provide evidence of the airburst phenomenon. These include both time- and frequency-domain observables.

We go on to estimate a detectable number of airbursts for InSight in a three-stage method. We firstly model the incident bolide population at the top of the martian atmosphere from direct observation of Earth's impactor population, scaled for planetary radius, incident velocity and density of impactors (see (4)).

Secondly, using a physical understanding of the airburst-forming process, we derive an airburst population from the impactor population. We find that very large $(>2 \mathrm{~m})$ and very small $(<0.1 \mathrm{~m})$ incident objects, will tend to impact the surface. In the first instance, because they are not slowed in the atmosphere and do not have time to meet the criteria for the onset of deformation. In the latter case, because they are slowed sufficiently that the dynamic pressure never exceeds the compressive strength of the object. Only impactors in the energy range $10^{-5}-10^{0} \mathrm{kT}$ TNT will result in an airburst and we expect $\sim 1000$ events of this type per year.

In the final stage, we take into account atmospheric attenuation, air-to-ground coupling inefficiencies and the instrument capability to estimate a detectable number of events for InSight to be on the order of 10-200 per year.

We caution that our analysis contains considerable uncertainties due to many poorly constrained aspects of the source population, airburst process, and energy propagation. Our estimates should therefore be regarded as order of magnitude only. However, despite these uncertainties airbursts could provide a viable seismic source for InSight.

Acknowledgements This research was funded by the Natural Environmental Research Council, the Leverhulme Trust, and the UK Space Agency.

\section{References}

S.J. Arrowsmith, D.P. Drob, M.A.H. Hedlin, W. Edwards, A joint seismic and acoustic study of the Washington State bolide: observations and modeling. J. Geophys. Res., Atmos. 112(D9), 1984-2012 (2007)

G. Balco, J.O. Stone, Measuring the density of rock, sand, till, etc. UW Cosmogenic Nuclide Laboratory, methods and procedures, http://depts.washington.edu/cosmolab/chem.html (2003)

H.E. Bass, J.P. Chambers, Absorption of sound in the martian atmosphere. J. Acoust. Soc. Am. 109(6), 30693071 (2001)

P.A. Bland, N.A. Artemieva, The rate of small impacts on Earth. Meteorit. Planet. Sci. 41(4), 607-631 (2006)

Q. Brissaud, R. Martin, R.F. Garcia, D. Komatitsch, Finite-difference numerical modelling of gravitoacoustic wave propagation in a windy and attenuating atmosphere. Geophys. J. Int. 206, 308-327 (2016). doi:10.1093/gji/ggw121

D.T. Britt, G.J.S.J. Consolmagno, Stony meteorite porosities and densities: a review of the data through 2001. Meteorit. Planet. Sci. 38(8), 1161-1180 (2003)

P.G. Brown, D.O. Revelle, E. Tagliaferri, A.R. Hildebrand, An entry model for the Tagish Lake fireball using seismic, satellite and infrasound records. Meteorit. Planet. Sci. 37(5), 661-675 (2002a)

P. Brown, R.E. Spalding, D.O. ReVelle, E. Tagliaferri, S.P. Worden, The flux of small near-Earth objects colliding with the Earth. Nature 420(6913), 294-296 (2002b)

P.G. Brown, J.D. Assink, L. Astiz, R. Blaauw, M.B. Boslough, J. Borovička, N. Brachet, D. Brown, M. Campbell-Brown, L. Ceranna, et al., A 500-kiloton airburst over Chelyabinsk and an enhanced hazard from small impactors. Nature (2013) 
R.T. Carter, P.S. Jandir, M.E. Kress, Estimating the drag coefficients of meteorites for all mach number regimes, in Lunar and Planetary Science Conference. Lunar and Planetary Inst. Technical Report, vol. 40, 2009, p. 2059

Z. Ceplecha, D.O. ReVelle, Fragmentation model of meteoroid motion, mass loss, and radiation in the atmosphere. Meteorit. Planet. Sci. 40(1), 35-54 (2005)

E. Chaisson, S. McMillan, Astronomy today (2005)

G.S. Collins, H.J. Melosh, R.A. Marcus, Earth impact effects program: a web-based computer program for calculating the regional environmental consequences of a meteoroid impact on Earth. Meteorit. Planet. Sci. 40(6), 817-840 (2005)

J.A. Crocker, Seismic Waves from A-Bombs Detonated over a Land Mass, Technical report, DTIC Document, 1952

I.J. Daubar, A.S. McEwen, S. Byrne, M.R. Kennedy, B. Ivanov, The current martian cratering rate. Icarus 225, 506-516 (2013)

I. Daubar, C. Dundas, S. Byrne, P. Geissler, G. Bart, A.S. McEwen, P. Russell, M. Chojnacki, M. Golombek, Changes in blast zone albedo patterns around new martian impact craters. Icarus 267, 86-105 (2016)

A. Douglas, Forensic Seismology and Nuclear Test Bans (Cambridge University Press, Cambridge, 2013)

W.N. Edwards, D.W. Eaton, P.G. Brown, Seismic observations of meteors: coupling theory and observations. Rev. Geophys. 46(4), 4007 (2008)

W.N. Edwards, A.R. Hildebrand, SUPRACENTER: locating fireball terminal bursts in the atmosphere using seismic arrivals. Meteorit. Planet. Sci. 39(9), 1449-1460 (2004)

W.N. Edwards, D.W. Eaton, P.J. McCausland, D.O. ReVelle, P.G. Brown, Calibrating infrasonic to seismic coupling using the Stardust sample return capsule shockwave: Implications for seismic observations of meteors. J. Geophys. Res., Solid Earth (1978-2012) 112(B10) (2007)

R.F. Garcia, Q. Brissaud, L. Rolland, R. Martin, D. Komatitsch, A. Spiga, Finite-difference modeling of acoustic and gravity wave propagation in Mars atmosphere: application to infrasounds emitted by meteor impacts. Space Sci. Rev. (2016). doi:10.1007/s11214-016-0324-6

I.N. Gupta, R.A. Hartenberger, Seismic phases and scaling associated with small high-explosive surface shots. Bull. Seismol. Soc. Am. 71, 1731-1741 (1981)

A.D. Hanford, L.N. Long, The direct simulation of acoustics on Earth, Mars, and Titan. J. Acoust. Soc. Am. 125(2), 640-650 (2009)

W.K. Hartmann, Martian cratering 8: isochron refinement and the chronology of Mars. Icarus 174, 294-320 (2005)

J. Havskov, G. Alguacil, Instrumentation in Earthquake Seismology (Springer, Netherlands, 2004)

J.G. Hills, M.P. Goda, The fragmentation of small asteroids in the atmosphere. Astron. J. 105, 1114-1144 (1993)

A.J. Hodges, The drag coefficient of very high velocity spheres. J. Aeronaut. Sci. 24, 755-758 (1957)

E. Hoek, Strength of jointed rock masses. Geotechnique 33(3), 187-223 (1983)

B.A. Ivanov, Mars/Moon cratering rate ratio estimates. Space Sci. Rev. 96(1-4), 87-104 (2001)

B.A. Ivanov, D. Deniem, G. Neukum, Implementation of dynamic strength models into 2D hydrocodes: applications for atmospheric breakup and impact cratering. Int. J. Impact Eng. 20(1), 411-430 (1997)

D. Kuznetsova, M. Gritsevich, Identification of meteorite-producing events in Martian and Terrestrial atmosphere, in Lunar and Planetary Institute Science Conference Abstracts, vol. 45, 2014, p. 1220

M.C. Malin, K.S. Edgett, L.V. Posiolova, S.M. McColley, E.Z.N. Dobrea, Present-day impact cratering rate and contemporary gully activity on Mars. Science 314, 1573-1577 (2006)

D. Mimoun, M. Murdoch, P. Lognonné, K. Hurst, T. Pike, W.B. Banerdt, The Mars seismic noise model of the InSight mission. Space Sci. Rev. (2016, submitted)

D. Morrison, C.R. Chapman, P. Slovic, et al., The impact hazard, in Hazards Due to Comets and Asteroids, vol. 1, University of Arizona Press, 1994, p. 59

N. Murdoch, B. Kenda, T. Kawamura, A. Spiga, P. Lognonné, D. Mimoun, W.B. Banerdt, Estimations of the seismic pressure noise on mars determined from large eddy simulations and demonstration of pressure decorrelation techniques for the InSight mission. Space Sci. Rev. (2016, submitted)

Y. Nakamura, Clear identification of fundamental idea of Nakamura's technique and its applications, in Proceedings of the 12th World Conference on Earthquake Engineering, Auckland New Zealand, 2000

J.P.L. NASA, InSights into the Early Evolution of Terrestrial Planets, 2013. http://insight.jpl.nasa.gov/docs/ InSight_NASA_fact_sheet_rev3_June_2013_FC.pdf

M.P. Panning, Planned products of the Mars Structure Service for the InSight mission to Mars. Space Sci. Rev. (2016). doi:10.1007/s11214-016-0317-5

A. Petculescu, R.M. Lueptow, Atmospheric acoustics of Titan, Mars, Venus, and Earth. Icarus 186(2), 413419 (2007)

O. Popova, I. Nemtchinov, W.K. Hartmann, Bolides in the present and past martian atmosphere and effects on cratering processes. Meteorit. Planet. Sci. 38(6), 905-925 (2003) 
O. Popova, J. Borovička, W.K. Hartmann, P. Spurný, E. Gnos, I. Nemtchinov, J.M. Trigo-Rodríguez, Very low strengths of interplanetary meteoroids and small asteroids. Meteorit. Planet. Sci. 46, 1525-1550 (2011). doi:10.1111/j.1945-5100.2011.01247.x

D.O. Revelle, Historical detection of atmospheric impacts by large bolides using acoustic-gravity waves. Ann. N.Y. Acad. Sci. 822, 284 (1997)

D.O. ReVelle, Recent advances in bolide entry modeling: a bolide potpourri. Earth Moon Planets 95(1-4), 441-476 (2004)

D.O. Revelle, P.G. Brown, P. Spurnỳ, Entry dynamics and acoustics/infrasonic/seismic analysis for the Neuschwanstein meteorite fall. Meteorit. Planet. Sci. 39(10), 1605-1626 (2004)

V.P. Stulov, Transformation of the kinetic energy of a meteoroid during its breakup in the atmosphere, in Doklady Physics, vol. 55, Springer, 2010, pp. 366-367

N.A. Teanby, Predicted detection rates of regional-scale meteorite impacts on Mars with the insight shortperiod seismometer. Icarus 256, 49-62 (2015)

N.A. Teanby, J. Wookey, Seismic detection of meteorite impacts on Mars. Phys. Earth Planet. Inter. 186, 70-80 (2011)

G.A. Tirskiy, D.Y. Khanukaeva, The modeling of bolide terminal explosions. Earth Moon Planets 95(1-4), 513-520 (2004)

A. Tsuchiyama, E. Mashio, Y. Imai, T. Noguchi, Y. Miura, H. Yano, T. Nakamura, Strength measurement of carbonaceous chondrites and micrometeorites using micro compression testing machine. Meteorit. Planet. Sci. Suppl. 72, 5189 (2009)

J.S. Watkins, R.L. Kovach, Seismic investigation of the lunar regolith, in Lunar and Planetary Science Conference Proceedings, vol. 4, 1973, p. 2561

S.C. Werner, A.W. Harris, G. Neukum, B.A. Ivanov, The near-Earth asteroid size-frequency distribution: a snapshot of the lunar impactor size-frequency distribution. Icarus 156(1), 287-290 (2002)

M. Wilks, A seismological investigation into tectonic and hydrothermal processes at Aluto and Corbetti, two restless volcanoes in the Main Ethiopian Rift, $\mathrm{PhD}$ thesis, University of Bristol, 2016

J. Williams, Acoustic environment of the Martian surface. J. Geophys. Res., Planets (1991-2012) 106(E3), 5033-5041 (2001)

D.R. Williams, Mars fact sheet. NASA Goddard Space Flight Center: Greenbelt. http://nssdc.gsfc.nasa.gov/ planetary/factsheet/marsfact.html (April 5, 2000) (2004a)

D.R. Williams, NASA Earth fact sheet. http://nssdc.gsfc.nasa.gov/planetary/factsheet/earthfact.html 2 (2004b)

J.-P. Williams, A.V. Pathare, O. Aharonson, The production of small primary craters on Mars and the Moon. Icarus 235, 23-36 (2014) 